\section{SATELLITE LAUNCHERS Levelling the field}

\section{Paris}

FIFTEEN US delegates from different government departments last week met members of the council of the European Space Agency (ESA) in Paris to discuss the ground rules for commercial satellite launches. The aim is to put an end to a long dispute about the legitimate role of state development funds for commercial rocket launchers.

For the past six years, US commercial launcher manufacturers have complained that Europe's Arianespace is competing unfairly, using state money (through ESA) to develop its rocket launchers. In response, Arianespace has pointed out that the US shuttle was developed by NASA and that

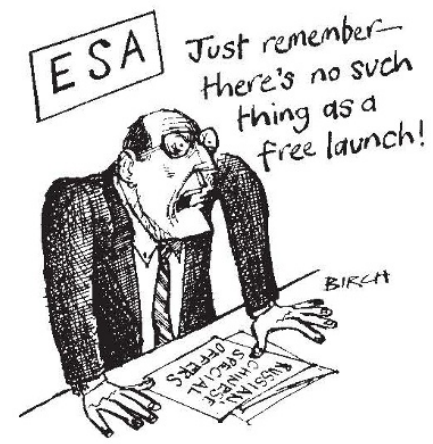

defence contracts keep the commercial launcher manufacturers in business.

Last week's meeting was the first of a long round of talks intended to produce a united front against launches offered by China and the Soviet Union. A launch aboard the Chinese Long March rocket can cost half as much as an Ariane launch.

An ESA spokesman said after the meetings that further discussions would be needed before any decisions on the definition of fair play would be made.

P.C.

\section{Fire down below}

\section{Tokyo}

JAPAN's National Space Development Agency (NASDA) is having no luck at all with development of the main engine of its next generation $\mathrm{H}$-II rocket. Last week, the engine again burst into flames during a test run at NASDA's Tanegashima Space Center.

The fire, the latest of a string of mishaps that have plagued the engine since tests began last year, appears to be the result of new problems. It broke out around the oxygen turbopump 16 seconds into a 200 second test firing and, although it was extinguished in about 20 minutes, it caused extensive damage to the engine.

NASDA officials are not yet prepared to say what effect the latest fire will have on the H-II launch schedule. But its effect is "under investigation" and Ryuichi Nagashima of NASDA's Program Plannning and Management Department says the fire is "serious" because "we are working on a very tight schedule".

D.S.

\title{
Study will break new ground
}

\section{London \& Washington}

UNITED States health officials gave their seal of approval last week to the most ambitious long-term study of the AIDS epidemic in North America ever conducted. As well as assessing the effectiveness of approved therapies such as AZT, the study will monitor the use of "underground' drugs and alternative therapies such as acupuncture and Chinese herbs. Hundreds of physicians and thousands of patients at over 40 community-based clinics in the United States and Canada are likely to participate.

In announcing the project, the Department of Health and Human Services Secretary, Louis Sullivan, whose past policies have been bitterly criticized by AIDS activists, said it "will result in the most comprehensive collection of information on HIV-infected persons amassed in the history of the AIDS epidemic". The study will be sponsored both by the National Institute of Allergy and Infectious Disease (NIAID), which coordinates the bulk of state-funded AIDS research in the United States, and the American Foundation for AIDS Research, a private funding organization.

The central aim is to gather data showing how AIDS progresses in different patient groups. So far, attention has focused largely on gay and bisexual men with AIDS, but the new study will look at a broader spectrum of the patient population including women, pregnant women and intravenous drug abusers. The study's designers hope that ultimately it will provide a detailed picture of the kinds of opportunistic infections affecting different patient groups and whether the pattern of infection is shifting with time.

\section{Doubts over 'wonderdrug'}

\section{London \& Washington}

THE African AIDS drug Kemron has touched off a heated debate with a racial twist. Hailed aa a 'wonderdrug' by its proponents, but considered worthless by sceptics, Kemron was given an optimistic launch earlier this year by Kenya's president Daniel arap Moi. Now it is in demand in the United States.

Kenyan scientists say their trials of the drug, whose activity they attribute to a tiny dose of $\alpha$-interferon, reveal marked benefits in over 1,000 patients, including 50 who they say are no longer HIV-positive. But tests of low doses of $\alpha$-interferon in the United States have yielded a mixed response. Some patients have reported no benefits; others claim modest to substantial improvements. Past US research on the effects of high doses of $\alpha$-interferon has proved equally inconclusive.

There is, however, another dimension
They also hope to analyse mysterious regional variations in opportunistic infections.

Anthony Fauci, director of NIAID, is boldly optimistic. The study should "help to identify areas where new research is needed, and may result in some new approaches to treatment", he says. But Martin Delaney of the AIDS organization Project Inform, which will participate in the study, thinks expectations are "higher than realistic". It will provide useful information on drug interactions and safety, he says, but would have had more impact five years ago.

The use of approved experimental drugs currently in clinical trial, such as $\mathrm{ddI}$, ddC, interleukin- $2, \alpha$ - and $\beta$-interferon and soluble CD4, will be monitored. Some of these are available through underground networks and ddI and ddC are likely to be distributed through official expanded access drug schemes.

Another area of interest is the use of alternative therapies and unorthodox drugs. Even though the study will provide only a rough guide to their effectiveness, anything "distinctly detrimental or miraculously favourable to the patient will show up", says Mathilde Krim, director of the American Foundation for AIDS Research.

Information on unorthodox drugs will be keenly awaited. With such drugs becoming increasingly available from underground markets, drug fads influenced by anecdotal reports of 'cures' abound. Compound $\mathrm{Q}$ - a drug claimed by some to have remarkable therapeutic effects hit the headlines earlier this year when two patients died using it.

David Concar \& Diane Gershon

to the debate. Black health officials in Africa and the United States say the drug has been played down by the whitedominated medical establishments of the West because of an ingrained distrust of African science.

This allegation has been flatly refuted by US health officials who say they are keeping an open mind on the matter. The chief problem is that the use of two different forms of the drug - powder and tablet - and a lack of placebo controls have rendered the data from African trials almost impossible to interpret.

Sadly, the confusion shows no sign of going away. Last month, a meeting convened by the World Health Organization specifically to discuss Kemron concluded that it is still too early to tell whether low doses of $\alpha$-interferon are of any value to AIDS patients.

David Concar \& Diane Gershon NATURE $\cdot$ VOL $347 \cdot 4$ OCTOBER 1990 